Volume: 1, Issue: 4, December 2016, Pages: 88-92, DOI: http://dx.doi.org/10.19082/ah88

\title{
SEGMENTATION OF ABNORMAL BLOOD CELLS TO AID LEUKEMIA DETECTION
}

\author{
Abdellatif Bouzid-Daho ${ }^{1}$, Mohamed Boughazi ${ }^{2}$, Camel Tanougast ${ }^{3}$
}

1: M.Sc, Ph.D. Student, Electronics Department, Faculty of Sciences of Engineers, University of Badji Mokhtar, Annaba, Algeria

2: Ph.D, Professor, Electronics Department, Faculty of Sciences of Engineers, University of Badji Mokhtar, Annaba, Algeria

3: Ph.D, Professor, Laboratory of Conception, Optimisation and Modelling Systems, University of Lorraine, Metz, France

\section{TYPE OF ARTICLE: COMMENTARY}

\begin{abstract}
The field of biomedical diagnosis has become very important in the evolution of medicine, and especially for the detection of cancer cells. In this paper, we will develop an algorithmic treatment by segmentation, using elements of mathematical morphology. The aim of our work is to obtain a maximum rate of recognition of leukemia. Our algorithmic diagram can segment, detect, characterize and describe cancerous blood cells (leukemia). This proposal is an important task in the interpretation and diagnosis of pathologies for hematologists. The experimental results applied on our microscopic medical images are encouraging for the identification of abnormal blood cells generally, and the distinction of leukemia especially, which shows the efficiency and rapidity of our algorithmic system.
\end{abstract}

KEYWORDS: Biomedical diagnosis, Mathematical morphology, Cancerous blood cells, Pathologies, Hematologists

\section{INTRODUCTION}

Cancers including leukemia and lymphoma can cause uncontrolled growth of an abnormal type of blood cell in the bone marrow, resulting in a greatly increased risk for infection and or serious bleeding Many cancers such as leukemia and lymphoma can cause uninhibited growth of an atypical type of blood cell in the bone marrow, which results in a significantly increased risk for infection and/or serious bleeding. There is not bad there are a many approaches in the literature used to identify as leukemia, V. Piuri et al. (1) proposed a method to automatically detect and classify Leukocytes into its subclasses, M. D. Joshi et al. (2) for segmentation and classification of white blood cells, S. J. Mishra, and A. P. Deshmukh (3) used Matlab to detect leukemia, Q. Wang et al. (4) for Identifying white blood cells and classification, and (5) they showed automatic detection of leukemia by segmentation, operated for the purpose of identifying or detect cancerous cells, but it remains the implementation of algorithms always limited with the various techniques This paper proposes a method of segmentation based on the morphological operators (6) to detect leukemia. This study focuses on the develop tools for the processing and analysis of microscopic medical images by the morphological operators is to extract from images acquired, the information useful for the diagnosis, reveal details difficult to collect to the naked eye, while avoiding the creation of artifacts, falsely informative. For this, the processing uses of algorithms, which allow you to act on the scanned image, this algorithmic processing composed essentially of the tools of mathematical morphology (7). This last is a methodology of image processing based on concepts, contains basic bricks (elementary operators) in a mathematical context varied.

\section{Correspondence:}

Abdellatif Bouzid-Daho, Ain-Tolba commune, wilaya of Ain-Temouchent, Algeria. Tel: +213.669866110 , E-mail: daholion@live.fr

Received: October 3, 2016, Accepted: November 12, 2016, Published: December 2016 iThenticate screening: October 5, 2016, English editing: November 23, 2016, Quality control: November 27, 2016 (C) 2016 The Authors. This is an open access article under the terms of the Creative Commons Attribution-NonCommercialNoDerivs License, which permits use and distribution in any medium, provided the original work is properly cited, the use is non-commercial and no modifications or adaptations are made. 


\section{MATERIAL AND METHODS}

\subsection{Research design and setting}

In this section, we present our medical context with some basic concepts to understand the results of our work, and then we begin the explanation of mathematical morphology, and we will conclude with the description of algorithmic processing proposed in this paper.

\subsection{Context medical}

White blood cells are a vital component of the blood system, which also contains red blood cells (8), platelets, and plasma. Even though they only account for as little as 1 percent of your blood, the impact that white blood cells have on your body is very significant. White blood cells, which are known as leukocytes, are essential for maintaining health and protection to your body. Consider white blood cells as your immunity cells. In a sense, they are in a continuous war against any invasion from illness or disease. They run through your bloodstream seeking out viruses, bacteria, and other foreign invaders that threaten your health. When a part of your body is suffering and a particular area is under attack, white blood cells charge into battle to help destroy the injurious substance and prevent illness. Your blood and lymphatic tissues store your white blood cells which are originally formed inside the bone marrow. Because some of your white blood cells have a lifespan of only one to three days, your bone marrow must constantly produce them.

\subsection{Mathematical Morphology}

The basic idea behind all the operators in mathematical morphology is to compare the set of objects to analyze another object of known form called the structuring element. The structuring element is a geometric figure simple to form known or arbitrary which can be a circle, a segment, a square or a triangle. The Form and the dimension of the structuring element noted $k$, allow you to extract specific forms when it is contained in a part of the whole $X$ or of its complement (9). By convention, it affects : 1) Value 0 if the point is ignored ; 2) Value 1 if the point is taken into account ; 3) $X$ : for the center. Two examples of structuring element as simple as represented on the Figure 1 . The Mathematical Morphology allows analyzing the image under two aspects (10): 1) Either as a set of forms taken on a background; it is then of the binary morphology where the transformations apply to the whole $X$ or to its complement $X_{c} ; 2$ ) Either as a function of grey levels; it is then to the morphology in grayscale where the transformations by analogy with the binary morphology, apply to the whole, bounded by the graph of the function $I(x, y)$ in grey levels.

\begin{tabular}{|l|l|l|}
\hline 1 & 1 & 1 \\
\hline 1 & $X$ & 1 \\
\hline 1 & 1 & 1 \\
\hline
\end{tabular}$\quad$\begin{tabular}{|c|c|c|}
0 & 1 & 0 \\
\hline 1 & $X$ & 1 \\
\hline 0 & 1 & 0 \\
\hline
\end{tabular}

(a)

(b)

Figure 1: Structuring elements: (a) [8 connexities], (b) [4 connexities]

\subsection{Algorithmic processing}

In this section, we present detailed steps of our proposed systems, to obtain a final result that shows the detection of abnormal cells. It typically starts with a median filter pre-processing step and then applying a different morphologic operator, which allows us to segment the original image and detect cancerous cells, Figure 2 describes the sequence of algorithmic processing more clearly.

\subsubsection{Preprocessing}

We have worked on images downloaded from (11), set of medical images is to use the blood cells of patients with leukemia. The median filter is normally used to improve image quality and reduce noise in our image.

\subsubsection{Morphologic operator}

Binary images might comprise of many imperfections, particularly the binary regions produced by simple thresholding, which are distorted by noise and texture $(12,13)$. Morphological image processing endeavors to remove these imperfections by accounting for the form and structure of the image. Morphological operators frequently take a binary image and a structuring element as input and integrate them using a set operator (intersection, union, inclusion, complement). Objects in the input image are processed based on characteristics of their shape, which are encoded in the structuring element. 


\subsubsection{Leukemia detection}

For better visualization of abnormal cells (leukemia), we applied the morphological elements with a basic segmentation.

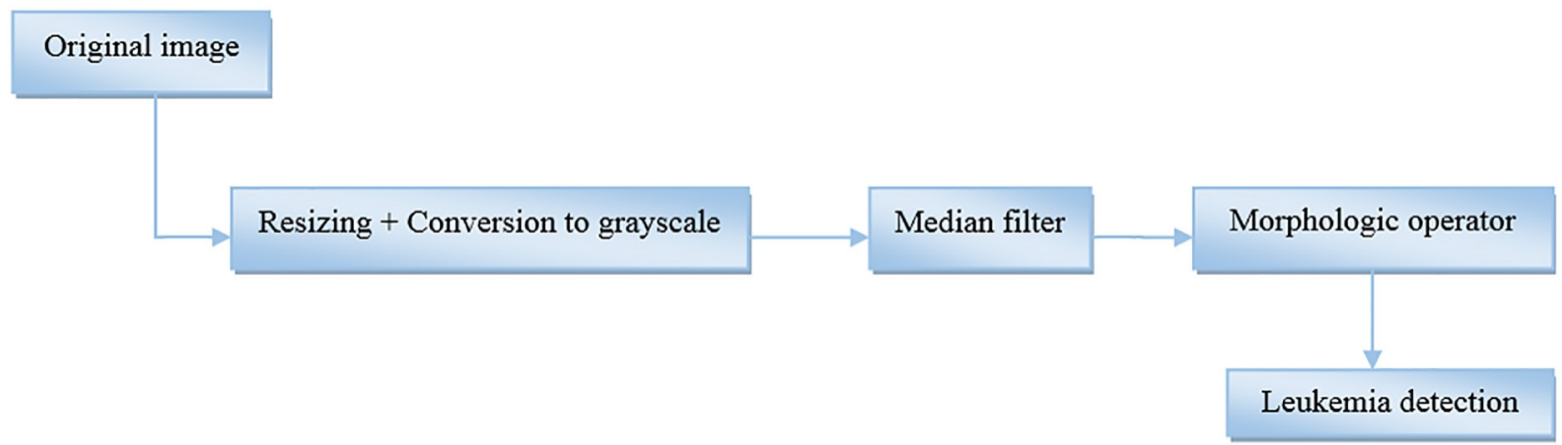

Figure 2: diagram of the proposed algorithm processing

\section{RESULTS}

In this section, we show the different results obtained after testing carried our algorithmic processing Matlab.

3.1. Step 1: Read image + resizing + conversion to grayscale (Figure 3).

It is necessary to resize the original image $256 * 256$ to facilitate algorithmic processing which results after we convert the RGB image to grayscale to process the result by morphological operators.

\subsection{Step 2: Filtering (Figure 4)}

A preprocessing step essentially based on filtering, we used median filter to reduce noise and improve its quality of image.

3.3. Step 3: Morphological operators (Leukemia detection) (Figure 5).

For better visualization of abnormal cells, we applied the morphological elements. The result shown in (Figure 5) gave a good detection of the class that displays the target objects (abnormal cells) with different colors.

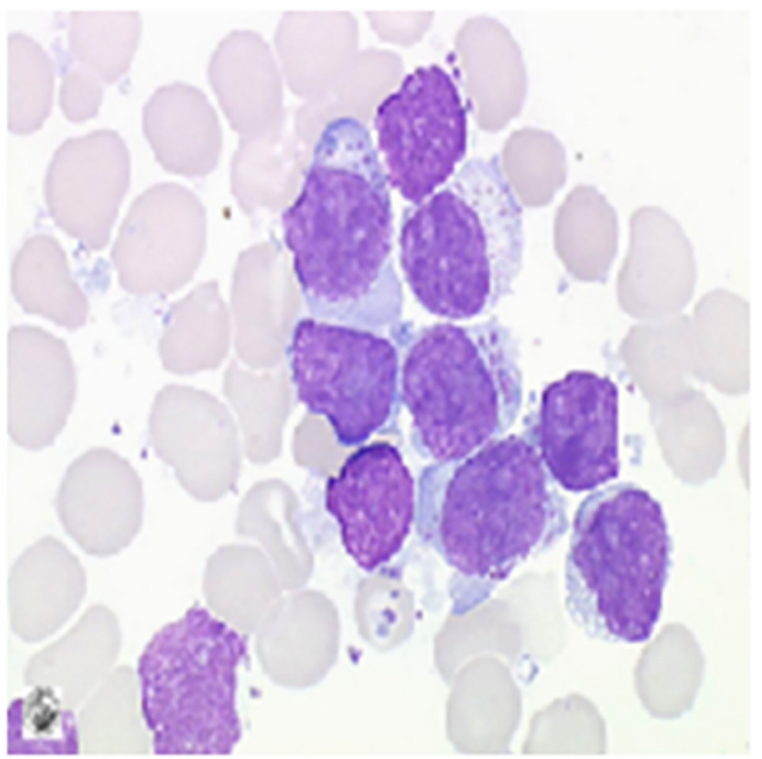

(a)

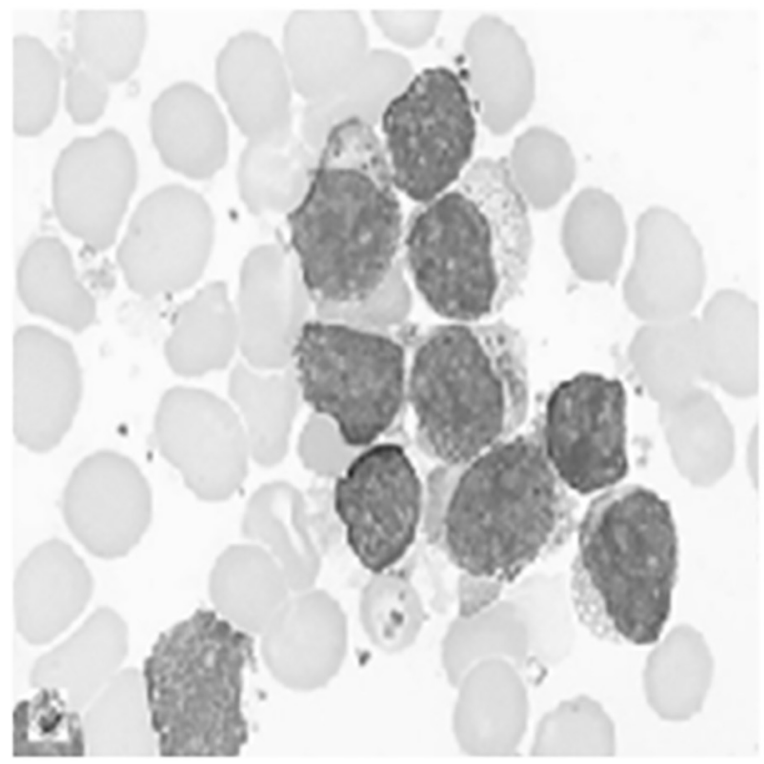

(b)

Figure 3: (a) Original image, (b) Grayscale image 


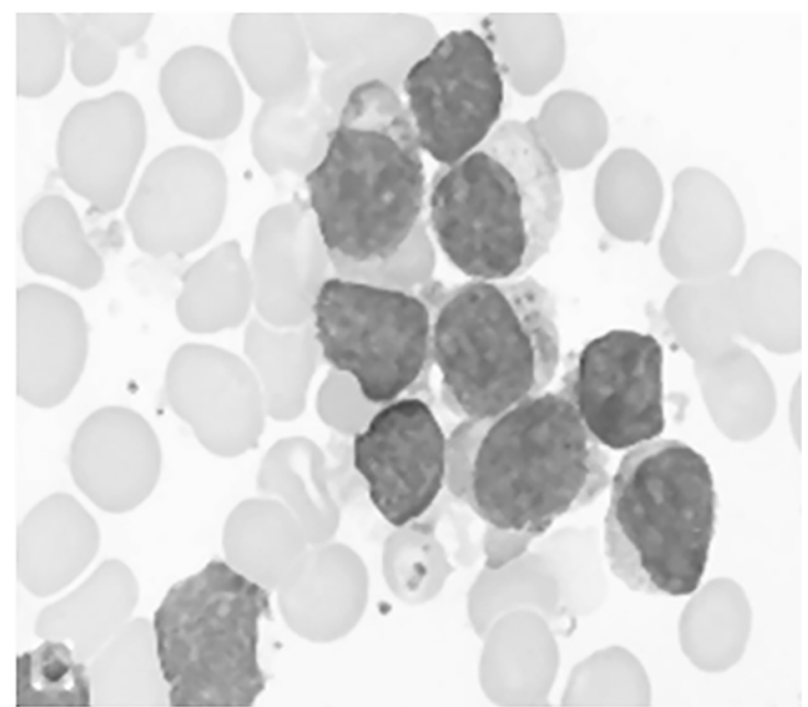

Figure 4: Image filter

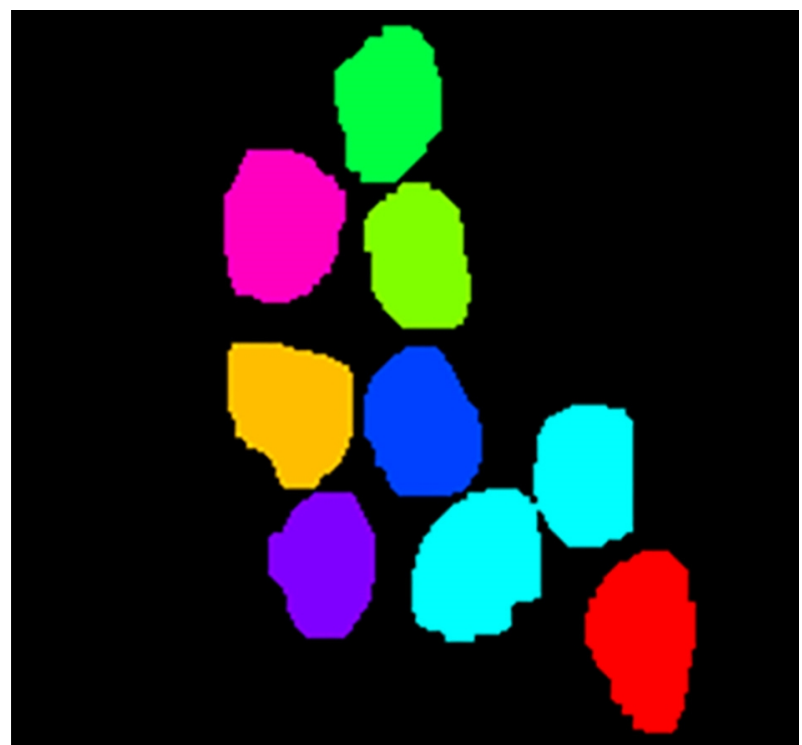

Figure 5: Application of morphological operators (Leukemia detection)

\section{CONCLUSIONS}

In this paper, we exploited the operators of mathematical morphology for our proposed system for the detection of abnormal blood cells, we have been able to create a biomedical diagnostic aid tool that allows us to transmit clinical information, accurate and clear in the form of processed images to facilitate the identification of cancerous blood cells and help doctors (hematologists) to follow the evolution of leukemia. Our proposed method has produced remarkable and satisfactory results. We are considering the development of biomedical instrumentation from this diagnostic aid system and integrating into microelectronics based on reconfigurable technologies.

\section{ACKNOWLEDGMENTS:}

My (Abdellatif Bouzid-Daho) sincere thanks to my supervisor Pr. Mohamed Boughazi professor at the University of Annaba from Algeria for the proposal of this research subject, their support allowed me to conduct my scientific research in good conditions and with a degree of freedom, guidance, the time he devoted to me, all his efforts and help. I offer here my sincere thanks to Pr. Saleh Toumi director of our laboratory LERICA for all the provisions of the hardware and software to succeed in this work. 


\section{CONFLICT OF INTEREST:}

There is no conflict of interest to be declared.

\section{AUTHORS' CONTRIBUTIONS:}

All authors contributed to this project and article equally. All authors read and approved the final manuscript.

\section{REFERENCES:}

1) Piuri V, Scotti F. Morphological classification of blood leucocytes by microscope images. InComputational Intelligence for Measurement Systems and Applications. 2004: 103-8. doi: 10.1109/cimsa.2004.1397242.

2) Joshi MD, Karode AH, Suralkar SR. White blood cells segmentation and classification to detect acute leukemia. International Journal of Emerging Trends and Technology in Computer Science (IJETICS). 2013; 2(3): 147-51.

3) Mishra S, Deshmukh A. Detection of leukemia using matlab. International Journal of Advanced Research in Electronics and Communication Engineering. 2015; 4(2): 394-8.

4) Wang Q, Chang L, Zhou M, Li Q, Liu H, Guo F. A spectral and morphologic method for white blood cell classification. Optics \& Laser Technology. 2016; 84: 144-8. doi: 10.1016/j.optlastec.2016.05.013.

5) Maini R, Aggarwal H. Study and comparison of various image edge detection techniques. International journal of image processing (IJIP). 2009; 3(1): 495-8.

6) Bouzid-Daho, M. Boughazi, and C. Tanougast. Algorithmic processing to aid in leukemia detection. Medical Technologies Journal. 2017; 1(1): 10-11.

7) Girault M, Hattori A, Kim H, Matsuura K, Odaka M, Terazono H, Yasuda K. Algorithm for the precise detection of single and cluster cells in microfluidic applications. Cytometry Part A. 2016; 89(8): $731-41$. doi: 10.1002/cyto.a.22825. PMid:27111676.

8) Viswanathan P. Fuzzy C Means Detection of Leukemia Based on Morphological Contour Segmentation. Procedia Computer Science. 2015; 58: 84-90. doi: 10.1016/j.procs.2015.08.017.

9) Bouzid-Daho A, Boughazi M, Tanougast C. Etude Statistique de Bio- Images dans le but de Détecter les Cellules Sanguines Anormales. Proceeding dans La première édition du Congrès Annuel sur les Sciences \& Technologies Appliquées. 2016: 2.

10) Jackway P, Deriche M. Shim-space properties of the multiscale morphological dilation-erosion. IEEE Transactions on Pattern Analysis and Machine Intelligence. 1996; 18: 38-51. doi: 10.1109/34.476009.

11) Laboratoire d'Hématologie Cellulaire du CHU d'Angers. Banque d'images. 2017. Available from: http://www.hematocell.fr/index.php/banque-dimages.

12) Bouzid-Daho, M. Boughazi and C. Tanougast, "Classification of Blood Cells by Method K-means," Proceeding of the 3rd International Conference on Embedded Systems in Telecommunications and Instrumentation (ICESTI'16), In Annaba, Algeria, 2016; 19.

13) Bouzid-Daho A, Boughazi M. Segmentation of textured medical images: Approach of the k-means. Proceeding of the first International Conference on Computer Science's Complex Systems and their Applications (ICCSA'2016). In Oum El Bouaghi, Algeria, 2016; 156-161. 